\title{
NEW DESIGN PERSPECTIVE OF ACCESSORIES FOR MODERN WOMEN'S WEAR
}

\author{
Hala Muhammad Mustafa SULEIMAN *
}

Department of Garment and Textile, Faculty of Home Economics, Helwan University, Egypt

\begin{abstract}
The art of clothing supplements is one of the arts that has occupied an important position in the field of design because of its great impact on showing the beauty and elegance of clothing, as well as its connection with fashion, in which multiple styles and new treatments have become commonplace to keep up with tastes, innovations and rapid change in the design of clothes, where the designer of supplements innovates and creates using the The materials and tools are what he likes to achieve in the end a useful artistic work in which the aesthetic relations of the complement are confirmed, depending on the synthesis of new materials that open him a wider field and greater possibilities and alternatives that enable him to create and innovate completely freely, in accordance with his desires and artistic trends to reach modern contemporary designs in line with fashion. The research problem is represented in the possibility of presenting proposed designs for supplements of contemporary women's clothing based on the art of synthesis in a method of juxtaposing raw materials, adding them and the style of dressing, and reaching the opinions of specialists and consumers towards those designs, and the aim of the research is to identify the art of combining with a method of juxtaposing and adding materials and the style of toushe and trying to employ it in the development of a contemporary design vision for complements Women's clothing. The research followed the descriptive approach with analysis and application to answer the research questions and hypotheses, and was able The researcher designed and implemented a separate complementary number, belt and necklace, and used basic materials such as (decorative tapes - ropes - natural leather - neck strap) and auxiliary materials such as (shells - agate stones - pearl beads - parlet strings - metallic accessories of various shapes - plastic accessories - chains Metal - sherbet - metal sharks - leather strings - seashell buttons - metal staples - decorative ribbons - wool balls - ropes), and relied on the art of combining with the method of juxtaposing and adding materials and the toushe style. - An aesthetic and innovative axis - a functional axis (towards designs of separate clothing supplements carried out by research and positive consumer opinions.

Keywords

Design, Perspective, Accessories, Modern, Women's Wear.
\end{abstract}

\section{Introduction}

The design of clothing supplements is one of the arts that has occupied an important position in the field of design because of its great impact in showing the beauty of clothing and its elegance and the appearance of a renewed appearance always, where the design of clothing supplements is one of the areas of design that are characterized by a special nature because of its great impact on the appearance of clothes. In addition to being considered one of the important factors that clarify the extent of civilization progress and the economic recovery of the dress of a country, it reflects in its designs, decoration and colors the civilization and beliefs of the society to which it belongs (Nadia Khalil), and there is no doubt that it has a fundamental role in completing the outward appearance of women because it gives them more Selfconfidence, glamor, and the beauty of her outfit, whatever it was

Simple, and keeps her from getting bored of repeatedly using the same outfit. (SafaaSabry:)

* Corresponding author: homeecon@helwan.edu.eg 
Therefore, designing clothing accessories is nothing but a creative activity that includes innovative data that will meet

Human needs for decoration, which may be aesthetic, functional or economic, and this creative activity is a set of mental skills accompanied by a high capacity for feeling, which contributes to creating an appropriate atmosphere to imagine or visualize an innovative form of a clothing supplement work, and the construction of this form is subject to a process of organizing its vocabulary from Lines, spaces, blocks and spaces in a form that creates a visual pattern, so that this shape comes out in a form of aesthetic organization. (Medal Maher)

Supplements are subject to renewal and innovation processes from time to time due to their association with fashion, in which multiple styles and new treatments have become commonplace to keep up with tastes, innovations and rapid change in designClothes, whether in terms of shape, material and colors, and the art of designing clothing supplements requires an innovative designer and artist who possesses a delicate sense and conscious art, to seek inspiration from new sources that no one has dealt with before him, or to reformulate the sources, but in an innovative way, adding that new in his field of art, all that surrounds The designer has visual indications that invite him to think, contemplate, analyze, and desire an innovative approach, and this does not come unless the designer has the ability to extract, modify and put the elements into a new formulation that is not recognized (Rehab Rajab:), and the designer embodies his ideas with the materials because they are an essential element in the composition of the complement and defining Its characteristics and its artistic and plastic values, and the more the designer's knowledge of the material's capabilities expanded, this led to an increase in his artistic innovations, bringing innovative designs based on his imagination that are compatible with contemporary fashion trends and meet the requirements of women in terms of innovation and distinction. It represents one of the important plastic, aesthetic, and functional aspects in the field of clothing design that shows the culture and vision of the designer, his creative methods and his intellectual developments, in order to reach a special entity that is distinguished by him. He was divorced from him, trying to develop concepts related to complementation to form new directions, formulations, and innovative ideas indicating modernity in an attempt to change the established concepts of the complement and reFormulated in updated visions that prove the designer's originality in its handling. Since the modern trend in the field of clothing supplements requires the innovation of new and strange forms and different types of supplements, the results of many studies and research in the field of clothing supplements such as the study of (Aya) have shown

Wajih Muhammad: (She studied the art of quilling, "the art of wrapping colored paper," and 
the possibility of using it and employing it to make designs for separate and related supplements to women's clothing, and the results of the research resulted in positive opinions of specialists towards the proposed designs, as well as a study (Sabra Duaij Al-Fahd: (where she used paper waste) The color scheme has employed it in the design and implementation of women's clothing supplements, and the implemented designs have met the acceptance of specialists and consumers, and the study recommended the necessity to encourage small industries in the field of clothing supplements as they do not need a large capital and they open job opportunities for young graduates, and from studies that used new materials

Unconventional in designing and producing accessories for clothing comes a study (IsraaZain Al-Abidin:) which deals with many unconventional materials such as (paper, ropes, leather, woods, metals, beads, ribbons, ropes, hoses, wires) and has designed and produced clothing products and their accessories. By combining them and combining them with various other materials such as (zippers, belts, gloves, neck ties), the designs implemented have met with the acceptance of specialists in the field.Among the studies that dealt with designing women's clothing supplements and relied on the sources of inspiration in the design, the study (Nasreen Muhammad Ismail:) Where it dealt with the traditional Bedouin costumes in Egypt to be used in preparing a group

Of designs for contemporary clothes and their complementary combining originality and modernity, and the results of the research resulted in positive opinions of specialists as well as disposables, and in the study (Aya Mahmoud Mustafa:) the researcher presented a set of design proposals for decorative configurations based in her design on geometric shapes in the Egyptian folklore and implemented 2 sets to complement women's clothing The results found that there are statistically significant differences between the supplements implemented at the level of significance 0,01 according to the opinions of specialists and consumers, as well as a study where the researcher was inspired by her designs to make clothing supplements from metal rods in car tires and used silver, copper and gem stones of various sizes to design uniform supplements, and she was able to study AfraSaleh Al-Hassoun:

To come up with artistic and color treatments for the 12 innovative designs (bag - belt) by employing the elements of Kufic script and arabesque motifs, and the results of the study resulted in the specialists 'acceptance of the proposed designs as well as the positive consumers of the designs. In another study, (HamdahKhalifa, ImanKamel -) was inspired by art. Saudi popular and investing potentialThe technical and plasticity of the natural leather material in the production of innovative leather crafts and supplements in line with the market requirements, and in the study (Khadija Saeed, AbeerJameel) I was inspired by the garment decorations of 
the Harb tribe to make designs of complementary clothes with the aim of making use of the traditional clothes of the women of the tribe and adapting them in line with modernity by employing and implementing Decorative units for a modern innovative design

Through the synthesis of materials and the use of different techniques, where 2 clothing supplements were designed and were accepted by specialists in the field of clothing supplements. The study emphasized the importance of combining materials to produce clothing supplement designs. Among the studies that dealt with the production of clothing supplements and that had an important role in encouraging the establishment of small projects in the field of supplements, the study (Jihan Mahmoud and Wafa Muhammad:) aimed at making use of colored ribbons in the implementation of some clothing supplements through a training program for students of the fourth year majoring in economics My home is to encourage female graduates to implement small projects, and the implemented supplements have met with acceptance and success in light of the specialists 'evaluation averages of the evaluation axes, and the study (Sherif Muhammad Yusef): which aimed to make use of the remains of leather and remnants of jeans fabrics in making clothing supplements and devising artistic and technical methods in the field of synthesis to make designs Innovative clothing supplements capable of competition and creating job opportunities for youth, developing small enterprises, and achieving a beneficial return on the individual and society, and through the survey study of previous studies on designing women's clothing supplements, the researcher tried in this research to create a contemporary artistic design vision for the supplements of separate women's clothing using the art of combining in a juxtaposed manner. The materials, their addition, and the dressing technique are based on four basic materials such as (decorative tapes - ropes - soft leather). I sell - neck strap (and auxiliary materials such as) shells - agate stones - pearl beads - carton strings parlé - metal accessories of various shapes - plastic accessories metal chains - sherbet - metal coins - leather strings - seashell buttons - metal clamps decorative ribbons - balls Wool )

\section{Research Problem:}

The research problem is summarized in the main question: What is the possibility of presenting proposed designs for women's clothing supplements that find acceptance by professionals and consumers?

This question is divided into the following sub-questions:

1. What is the possibility of creating contemporary designs to complement the separate women's clothing using the art of combination?

2. What are the professional opinions of the suggested clothing supplement designs? 
3. What is the degree of consumer acceptance of the proposed clothing supplement designs?

\section{Honesty and Persistence:}

\section{First: A Questionnaire of Specialists}

Validity of the questionnaire: it means the ability of the questionnaire to measure what was put to measure it. Honesty using internal consistency between the total score of each axis and the total score of the questionnaire: The validity was calculated using the internal consistency by calculating the correlation coefficient (Pearson correlation coefficient) between the total score of each axis (the design aspect, the aesthetic and innovative aspect, the functional aspect) and the overall score.

\section{Second: Verify The Research Hypotheses:}

The first hypothesis: "There are statistically significant differences between the designs implemented in achieving the aesthetic and innovative aspect according to the opinions of specialists."

To verify this hypothesis, an analysis of variance was calculated for the average degrees of designs implemented in the extent of achieving the aesthetic and innovative aspect, according to the opinions of specialists.

\section{References:}

1. Aya Jujih Muhammad al-Sarid (1422), "Raising the clothes of women and their supplements, with remnants of fabrics, using the use of colored paper flannel", a master's thesis, published in the Faculty of Home Economics, Menoufia University.

2. Jehanem Muhammed Abd al-Hamid and Wafaa Muhammed Muhammed (1422): “A training program for the recruitment of colored tapes, and it is used to add fashion supplements and statements from them in investment projects for the demands", Research Researches, Consultations, Alexandria Journal for Academic Exchange, Volume 32, Volume 32.

3. Hosni Basha Ali Hassan (1443) Contemporary Photography in Post-modernity, an introduction to the inspiration for the artistic values of experimental theater, Master's thesis, Faculty of Art Education, Helwan University

4. Khadija Sa id Misfer and Abeer Jameela (1422): "Dressing Supplements Inspired by the Clothing Decorations of any Tribe of War" Journal of Quality Education Research, Issue 13, Part 1.

5. Rehab Rajab Mahmoud (1420) "Fashion design is scientific studies and artistic visions", Dar Al Uloom, Cairo.

6. Sherif Mohamed Youssef (1422), "Benefiting from the Mentolife of Remnants of Leather, 
Textiles, Jeans, Designs and Supplements of Clothes," a master's thesis published, Faculty of Home Economics, University of Menoufia.

7. Sabra Duaij Al-Fahd (1422) "Development of a New Entrance to the Design of Clothes to Confront the Labor Market", Science and Arts Journal, Studies and Research, Vol. Twentyseventh, Issue Two.

8. Safaa Sabri Ibrahim (1441). Some fashion supplements affected the attire of elegance for university students, a master's thesis, Faculty of Specific Education, Mansoura University.

9. Afrarra Sarr Al-Hasroun (1422), to enrich the designs of the original decoration, as well as the women's clothing, with the combination of the kaufi and the ornaments of the Arabiskbas by using the computer account. "The letter of Majisir, the University of Al-Qassim, the College of Sami and the Home Economy.

10. The adequacy of Solomon et al. (1442), "Ventolifical materials in Egyptian heritage and the use of definitions of contemporary fashion designs", The Anglo-Egyptian Library, Cairo.

11. Nadia Mahmoud Khalil (2111): "Clothing Supplements," Accessories for Elegance and Beauty, Dar Al Fikr Al Arabi, Cairo.

12. Naderara Muhammed, Rudd Khalir (1445), the mutual relationship between the clothes and the complements "in the interest of the Fifth International Conference of the Division of Textile Industry.

13. Nagwa Shukri, Soha Ahmad (1441) "Formation on the Manichaan", Dar Al Fikr Al Arabi, Cairo.

14. We praise him, Caliph Abdel-Moneim, Iman Kamil Ghanem (1421): “A proposed program to take advantage of the traditional and artistic methods of natural mountains as an input for human development for graduates of the College of Design and Home Economics" Journal of Education College, University of the Year 1.

15. Nisreen Muhammed Ismail Khader (1425), “The Aesthetics and Functional Values of Some Bedouin Traditional Costumes in Egypt as an Entrance to Enriching Contemporary Clothing Designs and Their Supplements", unpublished PhD thesis, Faculty of Education, University of Menoufia.

16. Harajar Brad, Al-Rashed, Egypt, Artfi (1422): “An analytical study of the various masks of peoples and their aesthetic use to enrich women's clothes and their supplements, a master's thesis, Faculty of Home Economics, University of Menoufia.

17. Sammahir (1442): "The possibility of benefiting from the electronic computer systems to have aesthetic and functional effects inspired by Islamic art and applying them in the designs of complementary Alazi”, a letter by Majsater, College of Home Economics, University of 
Menoufia.

18. Hatsimir Ahmed Hafez (1422): "Metal rings in car tires as your sources of inspiration for designs and accessories for clothes" The Scientific Journal of the Amsia Society (Education for Tarif Art), Issue 5.

19. Sanjak Ibrahim Mustafa MUHAMMAD, Naglaa Ezzat Ahmed MAHMOUD, CREATING MODERN DESIGNS FOR NARROW INTERIOR SPACES INSPIRED BY THE ART OF ORIGAMI, International Journal of Design and Fashion Studies, Vol. 1, No. 1, 2018, pp. 1316.

20. Dina Ahmed NAFADY, CREATIVE INTEGRATION OF VARIOUS PRINTING TECHNIQUES AND THE AESTHETICS OF CONTEMPORARY SAUDI PLASTIC ART TO CREATE PRINTED FASHION DESIGNS, International Journal of Design and Fashion Studies, Vol. 1, No. 1, 2018, pp. 17-20.

21. Rehab Adel Shaker EL-FISHAWY, DESIGN OF MULTI-WEAR ACCESSORIES CLOTHING AS A CONTEMPORARY FASHION INSPIRED BY THE TRADITIONAL CLOTHING OF MENOUFIA, International Journal of Design and Fashion Studies, Vol. 1, No. 1, 2018, pp. 21-26.

Received: July 3, 2018

Accepted: September 8, 2018 